\title{
Raciocínio lógico na compreensão de texto
}

\author{
Amariles Alves Rodrigues \\ Maria da Graça Bompastor Borges Dias \\ Antonio Roazzi \\ Universidade Federal de Pernambuco
}

\begin{abstract}
Resumo
Lea, O’Brien, Fish, Noveck e Braine (1990) investigaram inferências lógicas efetuadas por informantes universitários do curso de Psicologia, durante leitura, e encontraram que informantes realizam inferências da lógica proposicional de maneira espontânea e automática. Perguntou-se: será que os alunos de Matemática demonstram raciocínio lógico mais desenvolvido que os alunos de Letras, tendo como responsáveis as disciplinas por eles cursadas? Informantes dos dois cursos foram entrevistados com o objetivo de investigar se o trabalho mental exigido pelas disciplinas cursadas favorece ou não o desenvolvimento do raciocínio lógico. Todos passaram por duas fases: tarefa de conclusão e tarefa de reconhecimento. Na primeira responderam a problemas silogísticos, e na segunda indicaram informações literais e inferenciais apresentadas nas histórias, com objetivo de observar se eles reconheceriam as sentenças como informações presentes no texto ou eram resultados de inferências feitas. A primeira tarefa confirmou que os informantes realizam inferências automaticamente. Na segunda tarefa os mesmos acreditaram que a paráfrase tinha sido apresentada explicitamente no texto, e raramente acreditavam que as sentenças foram resultados de inferências realizadas por eles. $O$ desempenho dos estudantes de Letras foi melhor de que os de Matemática.
\end{abstract}

Palavras-chave: Inferências lógicas, Paráfrases, Silogismos.

\begin{abstract}
Logical reasoning in text comprehension

Lea, O'Brien, Fish, Noveck e Braine (1990) investigated a variety of inferences in text of comprehension with undergraduate psychology students and the results showed that subjects carried out the proposional logical inferences spontaneous by automatically manner. These investigation explores whether mathematic students demonstrate logic reasoning better than letters students. Students from the two courses were studied with the aim of knowning whether the students could solve the logical reasoning tasks. The subjects performed two tasks: a task of Conclusion and a task of Recognition. On the first task, the subjects answered sylogistic problems and on the second they had to distinguish sentences with the aim to observe if they could recognized if the informations were in the text or were inferences made. The first task confirmed that the subjects authomaticaly used the inferences. On the second task, the subjects believed that the paraphases of the model had been explicitly presented in the text, and rarely believed that the sentences were results of inferences that they had made. The performance of literature students were better than mathematic students.
\end{abstract}

Keywords: Logical inferences, Paraphrases, Syllogisms.

$\mathrm{B}$ raine e Rumain (1983), comentando Henle (1962), declaram que as características da compreensão são as maiores fontes de erro por alterarem o comportamento nas tarefas de raciocínio. Para esses autores exis- tem dois tipos de compreensão da linguagem: a ordinária, que tem como objetivo encontrar o significado que o emissor pretende na declaração, e a analítica que, diferentemente, tem o propósito de descobrir o significado da sentença e 
o que ela representa por ela mesma. Este tipo de compreensão procura resolver as sofisticadas tarefas verbais encontradas em um texto.

Segundo Braine e Rumain (1983), para a compreensão de texto o leitor/ouvinte tanto utiliza o raciocínio lógico para a compreensão analítica, como o raciocínio prático para compreensão ordinária. A compreensão analítica, em oposição à ordinária, requer mais cuidado e, por exigir mais habilidade mental, acarreta grandes diferenças entre adultos. A distinção que aqui se faz entre compreensão ordinária e analítica é relevante porque o raciocínio lógico formal utilizado na resolução dos diferentes tipos de silogismos exige a compreensão analítica de suas premissas. Esta, no entanto, poderá não ser usada deixando o informante de determinar conclusões corretas e recorrer a falácias, quando influenciado pelo conteúdo das premissas, por suas crenças ou por não possuir habilidades que ela requer.

Esses autores argumentam ainda que o raciocínio dedutivo preside ou condiciona praticamente a totalidade do comportamento diário, e que tanto as mais simples ações, reações ou atitudes quanto as mais complexas, implicam em raciocínio. Observa-se, porém, que esse raciocínio formal que vem das premissas é algo que emerge de exercício especializado, de um ensino sistemático e tem o aparecimento mais tardio na evolução da cultura humana. O raciocínio prático é, sem dúvida, mais antigo, provavelmente tão antigo quanto a organização da linguagem. Nem sempre, entretanto, tem-se a consciência de se estar elaborando em si mesmo, um silogismo completo. Às vezes, o que aflora no plano da consciência é apenas a conclusão, traduzida em expressão verbal, em ações ou em comandos. Mas, antes dela, ou melhor, por baixo dela, subjaz como nos icebergs, uma elaborada série de processos mentais, que fornece os elementos ou dados para a generalização presente no silogismo.

Esse raciocínio exige pensamento lógico, que, segundo Piaget (1972), já se encontra desenvolvido no indivíduo adulto. Raciocinar logicamente deveria então, habilitá-lo a tomar posições e solucionar questionamentos, facilitando a resolução de problemas. Carraher (1983) aponta duas vantagens para o estudo da lógica. Primeiro, com seu uso, o informante tem mais facilidade em organizar e apresentar idéias e, conseqüentemente, suas declarações terão fundamentação mais clara e coerente. Segundo, o informante analisa com maior facilidade as idéias apresentadas por outros, sabendo interpretar argumentos complexos, esmiuçando-os com nitidez, para conseguir conclusões claras e coerentes. Essa segunda vantagem mostra-se importante pois o leitor, na maioria das vezes, terá como tarefa a interpretação de idéias alheias que dele exigirão pensamento lógico para conseguir conclusões claras e específicas.
Assim, o uso do raciocínio é um fenômeno comum na vida do ser humano, pois situações problemáticas aparecemlhe freqüentemente. Ao se ler, muitas vezes, é necessário que se analisem posicionamentos que exigem pensamentos lógicos, comumente usados para equacionar problemas. Pode-se dizer que produção e compreensão de textos podem ser tomadas como atividades de resolução de problema, apesar desta semelhança, implicar habilidades diferentes. Enquanto a produção implica a "tradução do conhecimento do informante em palavras, a compreensão implica a tradução das palavras em conhecimento pelo leitor". Desta forma, a complexidade dos processos mentais subjacentes à leitura requer estudo minucioso por parte de psicólogos e educadores.

A literatura sobre os modelos de leitura oferece diversidade de compreensões sobre o assunto, mas isto se torna profícuo na medida em que educadores comprometidos podem selecionar informações que os ajudarão a orientar seus alunos, eficientemente, nesta atividade. $\mathrm{O}$ ato de compreender envolve um conjunto de técnicas e estratégias mentais que justificam o termo "faculdade" que é dado aos processos cognitivos responsáveis pela compreensão de texto; afirmando-se assim, que esta depende de uma série de fatores lingüísticos e extralingüísticos e sendo algo muito mais complexo que apenas decifração de sentenças. A crítica de Goodman (1967) sobre leitura declara que ela "não é uma percepção única do conhecimento retirado", vê-la "como um processo de seleção que se dá como um jogo, com avanços de predições, recuos para correções" (p.128) que se fazem linearmente sem produzir compreensões definidas. A leitura adulta é uma atividade que exige elaborações semânticas, lógicas e culturais, que envolvem conhecimentos léxicos, raciocínio lógico formal e aspectos sócio-culturais. A constatação de grande diversidade entre as respostas encontradas nas versões de um mesmo texto é comum para pesquisadores que investigam essa tarefa. A eficácia da leitura depende das informações que lhe forem tiradas, uma vez que a compreensão é parte intrínseca da própria leitura e fundamental a ela.

Marcuschi (1989) argumenta que "a compreensão é um processo criativo e ativo, sobretudo construtivo, que vai além da informação textual" (p. 2). Goodman (1967) sugere que a compreensão é um processo complexo que envolve percepção de elementos visuais, seleção de saliências textuais e predição, confrontação e testagem de hipóteses.

Segundo Kleiman (1997), a compreensão de texto parece amiúde uma tarefa difícil, porque o próprio objeto a ser compreendido é complexo e possui uma rede de relações sintáticas, lexicais, semânticas, pragmáticas, dentro da estrutura da sentença, do período, do parágrafo, relações estas que tornam o objeto rico demais para uma percepção rápi- 
da, imediata e total. A leitura vista tanto como uma atividade a ser ensinada na escola, tanto como mero pretexto para outras atividades, está embasada em modelos que buscam dar conta de todos os seus aspectos.

Esses modelos lidam com os aspectos cognitivos da leitura, isto é, aspectos ligados à relação entre o informante leitor e o texto enquanto objeto, e entre linguagem escrita e compreensão, memória e inferência.

O conhecimento do aspecto psicológico, cognitivo da leitura é importante porque ele pode alertar, de maneira segura, contra práticas pedagógicas que inibem o desenvolvimento de estratégias adequadas para o processo de compreensão de texto. Por esta razão, a leitura tem conseguido tornar-se, atualmente, preocupação constante de pesquisadores que a vêem como atividade responsável pelo sucesso do estudante por estar sempre presente no indivíduo que participa de uma sociedade letrada.

Yuill e Oakhill (1991) observam que informantes adultos possuem habilidades de leitura que os auxiliam na compreensão de um texto e utilizam diferentes estratégias para consegui-lo. Bartlett (1932, citado em Yuill e Oakhill, 1991) argumenta que o significado não é inerente ao texto, mas é construído na interação entre conhecimentos do leitor e informações contidas no texto. É em contato com ele que o leitor faz emergir informações que, relacionadas, trarão o entendimento total da mensagem em uma verdadeira procura de significados. Para isto, o leitor utiliza habilidades, que em outros estudos já foram experimentalmente testadas, como velocidade, automatização e decodificação das palavras, utilização da memória e observações sintático-semânticas da linguagem.

Para Yuill e Oakhill, a leitura fluente não é um pré-requisito para a compreensão de texto, mas que esta depende de uma razoável rapidez na identificação de palavras, havendo evidências de que leitores pouco habilidosos são vagarosos em decodificar palavras. Oakhill, Cain e Yuill (1994) sugerem, com base em seus resultados de pesquisa, que as limitações na memória de trabalho podem levar o leitor a dificuldades em integrar informações constantes em diferentes partes de um mesmo texto. Estas limitações, para estes autores, não devem ser tomadas simplesmente como mais um processo em que os leitores podem encontrar dificuldades e, sim, como uma possível causa subjacente às demais dificuldades no processamento de texto. Os autores vão ainda mais adiante e tomam a avaliação dos recursos da memória de trabalho como uma moldura a partir da qual é possível integrar os componentes de processamento e conhecimento requerido pela tarefa de compreensão.

Daí conclui-se que a concepção da compreensão de leitura está embasada em modelos bem definidos que lidam com os aspectos cognitivos inerentes a ela, isto é, aspectos ligados à relação entre o informante leitor e o texto enquanto objeto, entre linguagem escrita e compreensão, memória, inferência e pensamento. Esses modelos tentam incorporar aspectos sócio-culturais da leitura, uma vez que vão desde a percepção das letras até o uso do conhecimento armazenado na memória. No entanto, o assunto não se encontra completamente investigado.

Para entender uma leitura o leitor tem de elaborar informações que se manifestam nos textos exigindo uma variedade de inferências. Os diferentes tipos de inferência têm sido testados em estudos realizados não só com crianças (Oakhill et al., 1994), como com adultos (Lima, 1983).

Lea et al. (1990) avaliaram a compreensão de textos que envolviam situações silogísticas. Procuraram determinar não só a capacidade do informante em analisar o silogismo oferecido, como também verificar a consciência do informante quanto às informações adquiridas, ou melhor investigar a capacidade de atuação da memória do leitor, através da identificação de sentenças retiradas do texto lido. As diferentes situações oferecidas durante esse estudo mostraram que os informantes não hesitavam em afirmar que as informações por eles colhidas encontravam-se explicitamente no texto, quando, realmente, ali não se encontravam.

Os autores concluem que inferências são feitas espontaneamente na compreensão de texto, e que elas incluem inferências da lógica proposicional e que os informantes constróem inferências de conjunção, disjunção, condicional e negação (e, ou, se, não) quando presentes em um texto. Consideremos uma das história utilizadas por Lea et al. (1990) em que é apresentado o problema silogístico:

Jerry escolhe a roupa

1. Jerry está decidindo o que usar no encontro com os pais de sua noiva.

2. Gostaria de usar ou a camisa de listra, ou a de xadrez, pensou ele.

3. Se eu usar a camisa de listra, terei de usar a calça azul pois elas combinam; mas eu não sei onde a calça azul está.

4. Procurou no guarda-roupa pela camisa xadrez e viu que ela estava machucada, assim decidiu que não podia usá-la.

Em (1) e (2) existe a apresentação do problema que é a escolha da camisa a ser usada no encontro. Jerry tem duas opções (a camisa de listra ou a de xadrez) nesse momento entra a partícula disjuntiva OU. Logo em seguida, em (3) aparece a condicional SE que dificulta ainda mais a resolução do informante, porém só em (4) é oferecida a última informação que o levará à conclusão válida: Jerry teria de procurar a calça azul. Para chegar a esta conclusão o leitor terá de relacionar as proposições apresentadas em (2) e (3) e ver a impossibilidade de uma das camisas (4) exigindo a escolha da outra. 
O modelo é assim representado com letras arbitrárias:

\section{Há D ou T.}

Se D então $\mathrm{V}$

Não há $\mathrm{T}$.

Assim, as diversas inferências realizadas, tanto lingüística, quando o leitor tem de relacionar anaforicamente que a primeira desinência verbal que aparece em 2 (Gostaria de usar ou a camisa de listra, ou a de xadrez, pensou ele.) e o pronome ele também em 2 referem-se a Jerry apresentado em 1 (Jerry está decidindo o que usar no encontro com os pais de sua noiva); quanto lógica, quando tiver de concluir em 4 (Procurou no guarda-roupa pela camisa xadrez e viu que ela estava machucada assim decidiu que não podia usála.) que Jerry terá de procurar a calça azul, fazem parte de um inferenciamento lógico necessário à compreensão do texto. Dentro da categorização de inferências também existem outras que demonstram sua importância, mas apenas as lógicas que responderão ao problema silogístico do texto serão objeto do presente estudo.

A hipótese de Lea et al. (1990) seria a de que quando os informantes lessem os textos aplicariam a lógica exigida pelo modelo do problema, integrando as informações apresentadas. Assim, na história de Jerry decidindo sobre o que usar, não levaria o leitor à inferência lógica até ser apresentada a informação (4). A disjunção OU, o condicional SE e a negativa "Não" deveriam ser entendidas e relacionadas, caso contrário seria difícil e talvez impossível determinar se as conclusões oferecidas completam, ou não, o silogismo. Os dados mostram que os informantes respondem espontânea e automaticamente como supunham.

O objetivo do presente estudo surgiu da necessidade de esclarecer "opiniões" sobre a compreensão de textos. Professores de diversos cursos, tanto da área de Ciências Humanas, quanto da área de Ciências Exatas, declaram que estudantes daquela área têm mais dificuldade em compreensão de texto de que os desta área. Procura-se assim, com a replicação do estudo de Lea et al. (1990), que envolve silogismos e compreensão de texto, encontrar respostas empíricas que expliquem a indagação: Será que universitários do curso de Matemática comparados aos de Letras são beneficiados pelas disciplinas que cursam, favorecendo o raciocínio lógico necessário à compreensão de um texto?

\section{Metodologia}

\section{Participantes}

Foram examinados 80 informantes, sendo 40 do curso de Ciências Exatas (Matemática) e 40 do curso de Ciências Humanas (Letras). Metade dos informantes de cada curso foi do sexo masculino e a outra metade do sexo feminino. Os informantes foram escolhidos aleatoriamente nos turnos manhã, tarde e noite e deveriam estar cursando o quarto período, quando já estariam envolvidos com as disciplinas específicas de cada curso, fora das disciplinas básicas a qualquer curso. Todos eram alunos de uma universidade pública.

\section{Delineamento}

A pesquisa foi desenvolvida em duas fases: Tarefa de Conclusão e de Tarefa de Reconhecimento. O propósito da Tarefa de Conclusão foi o de investigar a capacidade do informante em realizar inferências lógicas no processamento de um texto. Nesta tarefa foram empregados quatro fatores ou variáveis independentes: Curso (Matemática e Letras) X Sexo (masculino e feminino) X Modelos (seis modelos de raciocínio) X Tipos de história (válida e inválida). O propósito da Tarefa de Reconhecimento foi investigar se os participantes, através de suas respostas, distinguiriam informações explícitas no texto daquelas conseguidas por inferenciamento, através de informações implícitas. Para esta segunda fase foram empregadas seis variáveis independentes: Curso (Matemática e Letras) X Modelos (seis modelos de raciocínio) X Item (Paráfrase, Modelo e Não-modelo) e Sexo (masculino e feminino), X Tipos de história (válida e inválida) e Tipo de instrução (incompleta e completa).

A seqüência do material recebeu a denominação Ordem, possibilitando que cada informante fosse examinado, tanto na Tarefa de Conclusão como na Tarefa de Reconhecimento, nos seis modelos representados em 12 histórias, as quais continham ora conclusão válida, ora conclusão inválida, numa randomização do tipo quadrado latino.

\section{Material}

Constou de 14 textos, utilizados por Lea et al. (1990) com argumentos lógicos neles inseridos, organizados em pares por tipo de modelo lógico. Destes textos, sete ofereceram, no final de cada história, para análise do informante, resposta consistente com o problema e sete com resposta inconsistente, compondo a primeira fase, Tarefa de Conclusão. Para a segunda fase, Tarefa de Reconhecimento, também em relação às histórias, foram apresentadas três sentenças, cujo conteúdo representava o texto lido. Do total de histórias apenas 12 tiveram seus dados tratados estatisticamente, pois duas serviram apenas de prática para todos os informantes antes da tarefa propriamente dita.

Os textos continham quatro ou cinco períodos ${ }^{1}$, sendo diferenciados pelo conteúdo, mas, emparelhados por modelos da lógica formal (ver Quadro 1). Cada par de histórias com conteúdos diferentes, continha, para a primeira fase (Tarefa de Conclusão) conclusão válida e conclusão inválida, também chamadas consistente e inconsistente, 


\begin{tabular}{l|l}
\multicolumn{1}{c}{ Para treino } \\
\hline \multicolumn{1}{c|}{ Histórias } & \multicolumn{1}{c}{ Modelos } \\
\hline $\begin{array}{l}\text { 1 - Vírus } \\
\text { 2- Jerry escolhe a roupa }\end{array}$ & X ou F: Se F então A: não X. \\
\hline
\end{tabular}

\begin{tabular}{l|l}
\hline \multicolumn{1}{c|}{ Histórias } & \multicolumn{1}{c}{ Modelos } \\
\hline $\begin{array}{l}\text { A lâmpada } \\
\text { Teste de Física }\end{array}$ & $1-$ Ou K ou M ou F: não K e não M: então F. \\
\hline $\begin{array}{l}\text { Sociologia } \\
\text { Holmes }\end{array}$ & $\begin{array}{l}\text { - Se M e K então não W: tem M e é falso que não tem K, então } \\
\text { não W. }\end{array}$ \\
\hline $\begin{array}{l}\text { Cáries } \\
\text { O jantar }\end{array}$ & $3-$ Se J ou V então Z: Se O então J; Se N então V: tem O ou N \\
$\begin{array}{l}\text { A viagem } \\
\text { Discos }\end{array}$ & $4-$ Não os dois T e G: Se G então N ou D: G e não N. \\
\hline $\begin{array}{l}\text { Segurança } \\
\text { As bolachinhas }\end{array}$ & $5-$ Se V ou Z: então F: tem V e J: então F. \\
\hline $\begin{array}{l}\text { Plano de estudo } \\
\text { Xavier }\end{array}$ & $6-$ O e (K ou M ou Q): se X então não K: tem X. \\
\hline
\end{tabular}

respectivamente. Para a Tarefa de Reconhecimento, as três sentenças oferecidas eram tidas como paráfrase, resposta ao modelo e não-resposta ao modelo. Os pares de histórias contendo o mesmo modelo de raciocínio foram randomizadas e formaram dois conjuntos denominados Ordem 1 e Ordem 2.

Os textos utilizados neste estudo apresentam modelos da lógica proposicional, que autorizam concluir silogismos e permitem que as pessoas integrem informações, auxiliadas por elementos condicionais, conjuntivos, disjuntivos e de negação (se, e, ou e não) respectivamente. Foram escolhidos seis modelos de raciocínio para elucidação dos silogismos subjacentes aos textos aplicados.

\section{Procedimento}

$\mathrm{Na}$ tarefa de conclusão, os informantes foram divididos por curso, sexo e ordem. Esta última, constituída com o número mínimo de cinco informantes, foi organizada em Ordem 1 e Ordem 2 que representava a randomização dos pares de histórias válidas e inválidas; estes pares de história continham problemas semelhantes pela lógica formal e conteúdo diferenciados. A eles foi pedido que, depois de uma leitura silenciosa, respondessem com "sim" ou "não" à questão, se a sentença colocada no final do texto completava adequadamente o problema apresentado. Entregava-se a primeira história ao informante, enquanto o pesquisador dava as seguintes instruções:

Você lerá uma série de pequenas histórias e vai me dizer se a sentença final faz sentido com a história, respondendo sim se acha que faz sentido, e não se acha que não faz sentido.
$\mathrm{Na}$ tarefa de reconhecimento das sentenças, realizada logo após a primeira, observou-se a variável Tipo de Instrução: para metade dos informantes Instrução Incompleta e para a outra metade Instrução Completa. O experimentador entregou novamente cada história ao informante para que fizesse uma leitura rápida. Depois de recolhida, eram-lhe dadas as três sentenças (paráfrase, modelo em não-modelo), para que não mais com o texto à mão, respondesse se informações nelas contidas estavam presentes no texto.

Foram estas as instruções oferecidas pelo pesquisador:

Instrução Incompleta: "Observem as informações entregues a você agora e marque sim se elas aparecem no texto e não se não aparecem, embora possam ser inferidas da história".

Instrução Completa: "Observe as sentenças entregues a você agora e marque sim se as informações aparecem no texto, não necessariamente palavra por palavra, e não se elas não aparecem, embora seja possível inferilas da história".

Caso o informante oferecesse respostas iguais às três sentenças ("Sim" ou "Não" para todas elas) as mesmas eram devolvidas para que as revisse. Feito isso, o informante indicava qual delas ele teve mais certeza da presença no texto, no caso das respostas "Sim", e qual delas teve a mais certeza da ausência no texto, no caso da resposta "Não".

O procedimento adotado na tarefa de reconhecimento caso o informante oferecesse respostas iguais às três 
sentenças foi o seguinte: Se o informante oferecesse como resposta três "Sim" o experimentador lhe diria:

Releia as três frases e responda qual das três você tem mais certeza que aparece no texto.

A sentença apontada como aquela que o informante tinha mais certeza que aparecia no texto foi contabilizada como sim e as outras duas restantes foram como não.

Caso o informante oferecesse como resposta três "Não", o experimentador lhe diria:

Releia as três frases e responda qual das três você tem mais certeza que não aparece no texto.

A sentença apontada como aquela que o informante tinha mais certeza que não aparecia no texto, foi contabilizada como "Não", e as outras duas restantes como "Sim".

Como no estudo de Lea et al. (1990), o que se esperou foi que a primeira versão da instrução pudesse orientar alguns informantes a procurar igualdade de verbalização entre as sentenças das tarefas e sua memória do texto. Assim, como nenhuma sentença da tarefa de reconhecimento continha palavras idênticas às do texto, esperou-se que os informantes preferissem a resposta "Não" para esta versão. Embora se tivesse conhecimento da resposta espontânea e automática do leitor em relação ao problema silogístico, a memória poderia acusar, ou não, a presença da sentença no texto. A segunda versão contendo a frase "não necessariamente palavra por palavra" esperou-se a resposta "Sim", que apareceria em virtude desse acréscimo à instrução.

Isto quer dizer que embora as três sentenças (a paráfrase, a resposta ao modelo e a não-resposta ao modelo) não contivessem as mesmas palavras do texto, o conteúdo encerrado nas sentenças foi o mesmo processado, havendo apenas as instruções dadas na hora de responder à segunda fase, para controlar a resposta do leitor. Esperou-se que, quando o leitor ouvisse o acréscimo à instrução "não necessariamente palavra por palavra", pudesse escolher a resposta "Sim".

Quando o informante ofereceu respostas iguais, "Sim" ou "Não" para as três perguntas, registrando ape- nas um "Sim", quando todas fossem afirmativas, ou um "Não" quando todas fossem negativas.

$\mathrm{Na}$ fase de reconhecimento, os informantes não tiveram os textos disponíveis e as três sentenças (paráfrase, resposta ao modelo e a não resposta ao modelo) oferecidas para identificação ou não da presença das mesmas no texto, exigiram que acessassem a memória para definir sua resposta.

\section{Resultados}

Primeira fase: Análise da tarefa de conclusão

Pode-se verificar na Tabela 1 e 2, que a média de respostas corretas foi maior no curso de Letras do que no curso de Matemática, que as histórias com conclusões inválidas obtiveram maior número de acertos do que as válidas.

Para verificar estes resultados uma Análise de Variância para medidas repetidas foi realizada, tendo como fatores Modelos (6 tipos), Tipo de Histórias (Válidas e Inválidas), Curso (Matemática e Letras), Sexo (Feminino e Masculino), e como Variável Dependente as Respostas Corretas nas histórias ${ }^{2}$.

Esta análise produziu efeitos significativos para Sexo $(F(1,76)=7.03, p<0,01), \operatorname{Modelos}(F(5,380)=4.16, p<0,001)$ e Tipos de História $(F(1,76)=4.48, p<0,038)$. A Anova produziu também interações significativas entre Curso e Sexo $(F(1,76)=8.89, p<0,004)$, entre Curso, Sexo e Modelos $(F(5,380)=2.74, p<0,019)$, e Modelos e Tipo de Histórias $(F(5,380)=2,30, p<0,044)$. Em relação às variáveis Sexo $\mathrm{e}$ Tipos de Histórias, observa-se, assim, que o sexo feminino e as histórias inválidas obtiveram maior número de respostas "Sim" estatisticamente significativas do que o sexo masculino e as histórias válidas.

A fim de verificar o efeito principal da variável Modelos, as médias de respostas corretas em cada um dos seis modelos foram comparadas com o Teste de Newman-Keuls. Esta análise mostrou que os modelos 3 e 5 obtiveram significativamente mais respostas corretas do que o modelo 6

Tabela 1. Médias de respostas corretas na tarefa de conclusão em histórias válidas e inválidas em função do curso e do sexo

\begin{tabular}{cccccccc}
\hline \multirow{2}{*}{$\begin{array}{c}\text { Tipo de } \\
\text { história }\end{array}$} & \multicolumn{5}{c}{ Matemática } & \multicolumn{4}{c}{ Letras } & \multirow{2}{*}{ Total } \\
\cline { 2 - 7 } & Masculino & Feminino & Total & Masculino & Feminino & Total \\
\hline Válidas & 3,50 & 4,65 & 4,07 & 4,10 & 4,75 & 4,42 & 4,25 \\
Inválidas & 3,75 & 5,15 & 4,45 & 5,30 & 4,50 & 4,90 & 4,67 \\
Total & 3,62 & 4,90 & 4,26 & 4,70 & 4,62 & 4,66 & 4,46 \\
\hline
\end{tabular}


Tabela 2. Percentagens de respostas corretas na Tarefa de Conclusão em histórias válidas e inválidas, em função de curso, de sexo e de modelos

\begin{tabular}{|c|c|c|c|c|c|c|c|c|c|c|c|c|c|}
\hline \multicolumn{14}{|c|}{ Tipos de Histórias } \\
\hline \multirow[b]{2}{*}{ Curso } & \multirow[b]{2}{*}{$\begin{array}{c}\text { Modelos } \\
\text { Sexo }\end{array}$} & \multirow[b]{2}{*}{1} & \multicolumn{4}{|c|}{ Válidas } & \multicolumn{7}{|c|}{ Inválidas } \\
\hline & & & 2 & 3 & 4 & 5 & 6 & 1 & 2 & 3 & 4 & 5 & 6 \\
\hline \multirow[t]{2}{*}{ Matemática } & M & 60 & 60 & 55 & 60 & 70 & 45 & 60 & 45 & 75 & 50 & 70 & 75 \\
\hline & $\mathrm{F}$ & 75 & 85 & 80 & 85 & 80 & 60 & 90 & 75 & 95 & 100 & 85 & 70 \\
\hline \multirow[t]{3}{*}{ Letras } & M & 85 & 60 & 70 & 70 & 75 & 60 & 85 & 80 & 95 & 90 & 90 & 90 \\
\hline & $\mathrm{F}$ & 80 & 75 & 85 & 85 & 90 & 53 & 60 & 70 & 80 & 80 & 70 & 90 \\
\hline & $\begin{array}{l}\text { Média } \\
\text { Total }\end{array}$ & 75 & 70 & 72 & 75 & 78 & 53 & 73 & 67 & 86 & 80 & 78 & 81 \\
\hline
\end{tabular}

$(p<.05)$. Não houve diferenças significativas entre os outros modelos.

Para verificar a interação entre Modelos e Tipos de História, as médias de respostas corretas nos seis pares de modelos das histórias válidas foram comparadas com o Teste de Newman-Keuls. Esta análise mostrou que um número significativamente maior de respostas corretas foi dado aos modelos 1, 2, 4 e 5, quando comparados ao modelo $6(p<0,01)$. Este também recebeu significativamente menos respostas do que o modelo 3. As interações significativas estão demonstradas nas Figuras 1, 2 e 3.

Este mesmo teste, quando aplicado aos modelos das histórias inválidas, não mostrou diferença significativa entre eles.

A Figura 1, numa interação entre curso e sexo, informa que, enquanto o curso de Letras apresenta-se horizontalmente entre masculino e feminino, o curso de Matemática apresenta uma inclinação descendente entre feminino e masculino em relação ao número de acertos.
A Figura 2 mostra a interação significativa entre Curso, Modelos e Sexo. Observa-se que em relação a Modelos, no curso de Letras os dois sexos estão muito próximos quanto ao número de acertos apresentados, havendo um declínio muito discreto em conjunto, no modelo 6 , e um melhor número de respostas corretas do sexo masculino no modelo 1. No curso de Matemática, aparece esse mesmo declínio no modelo 6 , no entanto, o desempenho do sexo feminino foi sempre superior em todos os modelos.

A Figura 3, apresentando uma relação entre Modelos e tipo de histórias, informando que o modelo de raciocínio 6 , na história válida, foi o que recebeu menos acertos. A estrutura lógica deste modelo é apontada como responsável por sua baixa localização na Figura 3, pois o informante teve de conjugar um item com outros três, para depois eliminar um destes itens na dependência de um quinto item. Essa figura mostra que as histórias inválidas foram beneficiadas pela escolha do informante em

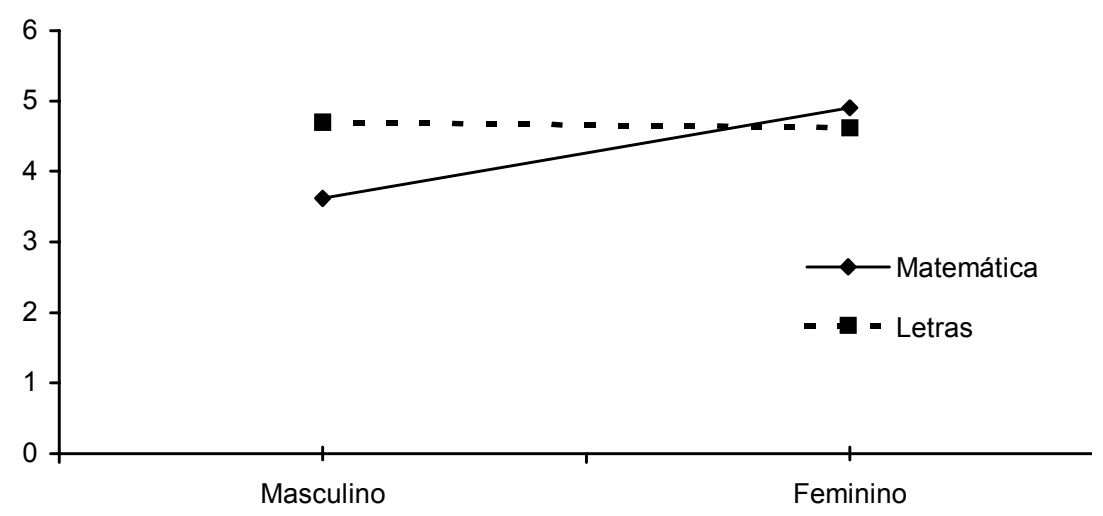

Figura 1. Médias das respostas corretas por curso e sexo 


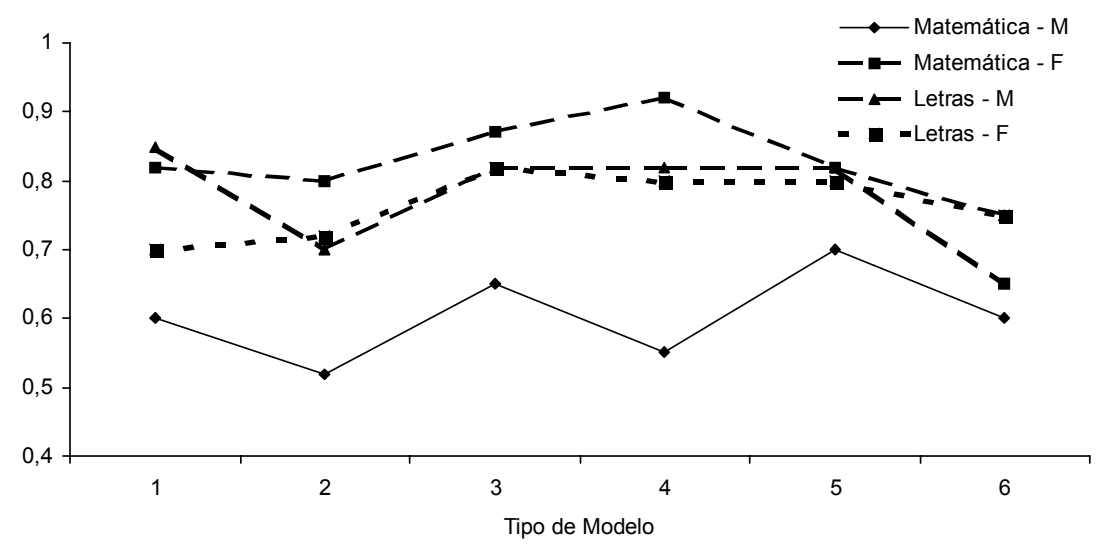

Figura 2. Médias das respostas corretas por curso, sexo e modelos

virtude de seu conteúdo, principalmente no modelo 3, conter informações contrárias aos conhecimentos de mundo dos informantes, levando-os a rejeitá-las.

Em relação a esta primeira fase, Tarefa de Conclusão, os informantes responderam corretamente a $74 \%$ dos silogismos apresentados, enquanto informantes do estudo de Lea et al. (1990) apresentaram 87\%. A média de respostas corretas por modelos, no entanto, variou entre $67 \%$ e $79 \%$, apresentando uma queda acentuada nos modelos 2 e 6 . Merece pontuar que este declínio foi apresentado no modelo 6 na história com conclusão inválida, em oposição ao modelo 3 , com histórias válida, cuja ascendência está demonstrada na Figura 3.

Segunda fase: Análise da tarefa de reconhecimento

Foram computadas, para esta tarefa as respostas "Sim" ou "Não" ("Sim" codificado como 1 e "Não" codi- ficado como 0), pela presença no texto, de uma das frases lidas pelos informantes, já anteriormente classificadas dentro de três itens: Paráfrase, Modelo e Não-modelo. Como dados para análise tomou-se o número de respostas corretas nos três itens. As afirmativas significavam que já haviam sido lidas pelos informantes, comprovando assim a presença delas nos textos.

Verifica-se nas Tabelas 3 e 4, que o número de respostas "Sim" foi mais alto para o item Paráfrase, seguido de Modelo e Não-modelo, resultado já encontrado por Lea et al. (1990). No entanto, quando se considera o fator tipo de Instrução (Tabela 4), os informantes do presente estudo obtiveram maior índice de respostas "Sim" nos itens Paráfrase e Modelo com instrução completa. A Tabela 5 não apresenta diferença considerável entre histórias válidas e inválidas dentro de cada item.

$\mathrm{Na}$ Tabela 6, encontram-se as médias de respostas "Sim" para a Tarefa de Reconhecimento nos três itens em

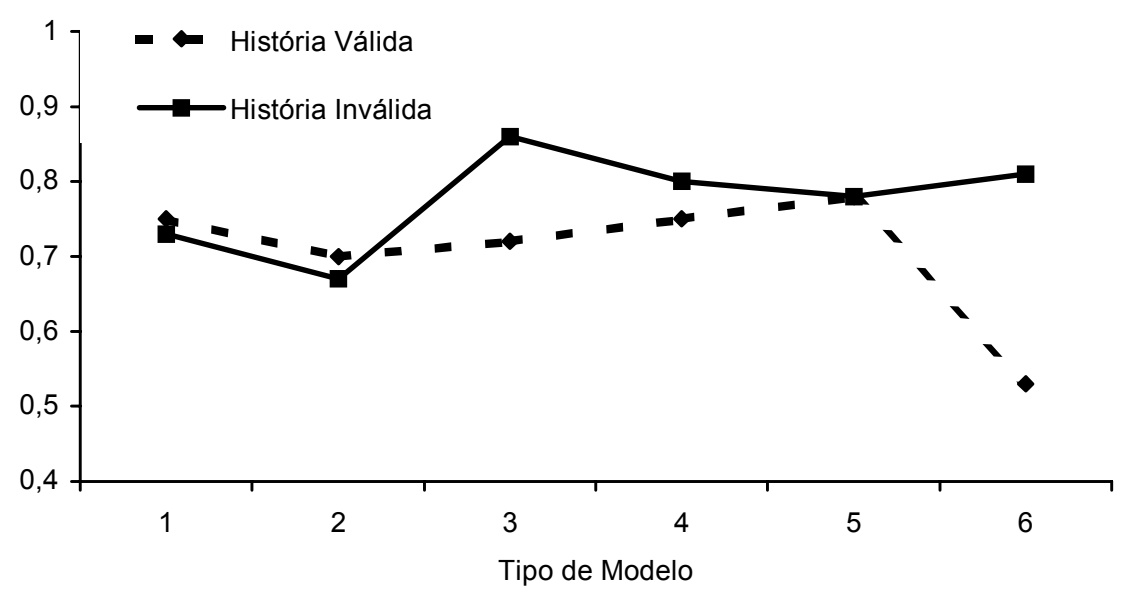

Figura 3. Médias de respostas corretas por modelo em função do tipo de história 
função do Curso, do Tipo de Instrução e do Tipo de História.

Nesta segunda fase, de Reconhecimento, três grandes análises estatísticas foram realizadas, tendo como fatores Modelos (6 tipos), Tipo de Instrução (instrução completa e incompleta) e Curso (Letras e Matemática). Como variável Dependente recorreu-se ao número de respostas "Sim" oferecidas para cada um dos itens: Paráfrase, Modelo e Não-modelo ${ }^{3}$.

Os testes estatísticos realizados para cada item obedeceram à variável tipo de história. Então, foram utilizadas as histórias válidas, depois as histórias inválidas e por último histórias válidas + inválidas.

Para as médias da Tabela 7 em função do Curso, Item e do Tipo de Instrução, necessárias se fazem observações por Curso.

\section{Paráfrases}

1.1. Para verificar os resultados foi realizada uma Análise de Variância com as histórias Válidas envolvendo como fatores Modelos (6 tipos), Tipo de Instrução (instrução incompleta e completa), e Curso (Letras e Matemática) e como variável dependente o número de respostas "Sim" para o item Paráfrase. Esta análise produziu efeitos significativos para Curso $(F(1,76)=5.88, p<0,02)$, e para Modelos $(F(5,380)=4.21, p<0,001)$. Nas histórias válidas o curso de Letras ofereceu mais respostas "Sim" (média 0,72) do que o curso de Matemática (média 0,61) (ver Tabela 1). Quanto ao efeito significativo para Modelos, o Teste de Newman-Keuls mostrou que a média de respostas "Sim" para o Modelo 1 foi significativamente maior do que o Modelo $5(p<0,01)$ e do que o Modelo 3 $(p<0,05)$.

Tabela 3. Percentagens de respostas SIM obtidos na tarefa de Reconhecimento em relação a itens nos experimentos de Lea e cols. e no atual

\begin{tabular}{ccc}
\hline Itens & Lea et al. & Atual \\
\hline Paráfrase & 89 & 66 \\
Modelo & 69 & 65 \\
Não-modelo & 15 & 31 \\
\hline
\end{tabular}

Tabela 4. Percentagens de respostas "Sim" na tarefa de reconhecimento em função do tipo de Instrução e dos itens

\begin{tabular}{cccc}
\hline Tipo & \multicolumn{3}{c}{ Itens } \\
\cline { 2 - 4 } de Instrução & Paráfrase & Modelo & Não-modelo \\
\hline Instrução Incompleta & 64 & 61 & 34 \\
Instrução Completa & 67 & 68 & 38 \\
\hline
\end{tabular}

Tabela 5. Percentagens de respostas SIM obtidas na tarefa de Reconhecimento em função do Curso e Modelo

\begin{tabular}{lccccccc}
\hline \multicolumn{1}{c}{ Curso } & \multicolumn{9}{c}{ Modelos } & \multicolumn{2}{c}{ MédiaTotal } \\
\hline & 1 & 2 & 3 & 4 & 5 & 6 & \\
\hline Matemática & 54 & 55 & 55 & 47 & 48 & 51 & 51 \\
Letras & 59 & 59 & 60 & 53 & 50 & 51 & 55 \\
Média Total & 56 & 57 & 57 & 50 & 49 & 51 & 53 \\
\hline
\end{tabular}


1.2. Para as histórias Inválidas, foi realizada uma Análise de Variância tendo como fatores os Modelos (6 tipos), Tipo de Instrução (2) e Curso (2) e como Variável Dependente o número de respostas "Sim", para o item Paráfrase. Esta análise apresentou um efeito significativo para Curso $(F(1,76)=5.97, p<0,02)$. Assim verifica-se que o curso de Letras obteve mais respostas "Sim" (média 0,70) do que o de Matemática (média 0,59) nas histórias inválidas.

1.3. A Análise de Variância realizada envolvendo histórias Válidas e Inválidas teve como fatores Modelo e Tipo de Instrução e Curso, e como variável dependente o número de respostas "Sim" para o item Paráfrase (ver Tabela 7).

Os efeitos significativos revelados foram: Curso $(F(1,76)=11,45, p<0,001)$ e Modelo $(F(5,380)=3,39$, $p<0,005)$. Assim, o curso de Letras ofereceu maior número de resposta "Sim" (média 0,70) nas Paráfrases que o de Matemática (média 0,60). Comparando as médias de respostas "Sim" nos dois tipos de histórias (válidas e inválidas) através do teste de Newman-Keuls, verifica-se que o Modelo 1 obteve maior número de respostas "Sim" do que o Modelo $5(p<0,01)$, do que o $4(p<0,01)$ e do que o $3(p<0,05)$.

\section{Modelo}

2.1. Foi realizada uma Análise de Variância com as histórias Válidas tendo como fatores Modelos e Tipo de Instrução e Curso e como Variável Dependente o número de respostas "Sim" para o item Modelo. Registraram-se efeitos significativos apenas para Tipo de Instrução $(F(1,76)=8,84, p<0,004)$. Os informantes que receberam instrução completa (média 0,73 ) ofereceram maior número de respostas "Sim" neste tipo de história do que instrução incompleta (média 0,60).

2.2. Já para as histórias Inválidas a Análise de Variância teve também como fatores Modelos e Tipo de Instrução e Curso, e como Variável Dependente o número de respostas "Sim" para o item Modelo. Houve apenas efeito significativo para Modelos $(F(5,380)=2,83, p<0,02)$. O teste de Newman-Keuls demonstrou que os modelos $1 \mathrm{e}$ 2 atingiram significativamente maior número de respostas "Sim" do que o Modelo $3(p<0,01)$.

2.3. Quando a Análise de Variância envolveu histórias Válidas e Inválidas, a análise demonstrou efeitos significativos para Curso $(F(1,76)=5,38, p<0,023)$, para Tipo de Instrução $(F(1,76)=5,38, p<0,023)$, e Modelo $(F(5,380)=$ $4,04, p<0,001)$. O curso de Matemática obteve menor número de respostas "Sim" $(0,61)$ nas histórias válidas e inválidas do que o de Letras (média 0,68). Quanto ao Tipo de Instrução, os informantes que receberam as Instruções Completas ofereceram mais respostas "Sim" (média $0,68)$ do que aqueles que receberam as Instruções Incompletas (média 0,61).

As médias de respostas "Sim" para cada modelo foram tratadas com o teste de Newman-Keuls que denotou os seguintes resultados: o Modelo 1 teve melhor resulta-

Tabela 6. Percentagens de respostas "Sim" para a tarefa de reconhecimento nos três itens em função do Curso, do Tipo de Instrução e do Tipo de história

\begin{tabular}{|c|c|c|c|c|c|c|}
\hline Curso & & & & Itens & & \\
\hline \multirow{7}{*}{ Matemática } & $\begin{array}{l}\text { Tipo de } \\
\text { Instrução }\end{array}$ & $\begin{array}{l}\text { Tipos de } \\
\text { História }\end{array}$ & Paráfrase & Modelo & Não-modelo & $\begin{array}{l}\text { Média } \\
\text { Total }\end{array}$ \\
\hline & \multirow{3}{*}{ Incompleta } & Válidas & 64 & 56 & 36 & 52 \\
\hline & & Inválidas & 59 & 56 & 37 & 51 \\
\hline & & Média Total & 61 & 56 & 36 & \\
\hline & \multirow{3}{*}{ Completa } & Válidas & 57 & 69 & 35 & 53 \\
\hline & & Inválidas & 60 & 63 & 32 & 51 \\
\hline & & Média Total & 58 & 66 & 33 & \\
\hline \multirow{6}{*}{ Letras } & \multirow{3}{*}{ Incompleta } & Válidas & 68 & 64 & 30 & 54 \\
\hline & & Inválidas & 63 & 68 & 34 & 54 \\
\hline & & Média Total & 65 & 66 & 32 & \\
\hline & \multirow{3}{*}{ Completa } & Válidas & 77 & 78 & 20 & 62 \\
\hline & & Inválidas & 77 & 63 & 26 & 55 \\
\hline & & Média & 77 & 70 & 23 & \\
\hline
\end{tabular}


Tabela 7. Percentagens de respostas "Sim" para a tarefa de Reconhecimento em relação a Curso, Tipo de instrução e Itens

\begin{tabular}{ccccccc}
\hline \multirow{2}{*}{ Curso } & & \multicolumn{5}{c}{ Itens } \\
\cline { 2 - 6 } \cline { 5 - 7 } Matemática & $\begin{array}{c}\text { Tipo de } \\
\text { Instrução }\end{array}$ & & Paráfrase & Modelo & Não Modelo & Média Total \\
\hline \multirow{3}{*}{ Letras } & Incompleta & 61 & 56 & 36 & 51 \\
& Completa & 60 & 63 & 32 & 51 \\
& Média Total & 61 & 60 & 34 & 54 \\
& Incompleta & 65 & 66 & 32 & 57 \\
& Completa & 77 & 70 & 23 & \\
\hline
\end{tabular}

do do que o Modelo $3(p<0,01)$ e do que o Modelo 4 $(p<0,05)$. O Modelo 2 também obteve significativamente maior números de respostas "Sim" do que o Modelo 3 $(p<0,01)$ e do que o Modelo $4(p<0,05)$.

\section{Não-modelo}

Para este item também três análises de variância foram realizadas: primeiro com histórias Válidas; segundo com histórias Inválidas, e terceiro com Válidas e Inválidas. Todas as análises tendo como fator os Modelos, Curso e Tipo de Instrução e como Variável Dependente o número de respostas "Sim".

3.1. Para as histórias Válidas, apresentaram-se como significativos os resultados em relação a Curso $(F(1,76)=$ $9,70, p<0,003)$; Tipo de Instrução $(F(1,76)=4,71, p<0,033)$; e Modelos $(F(5,380)=5,69, p<0,000)$. O curso de Matemática ofereceu mais respostas "Sim" $(0,36)$ do que o curso de Letras $(0,25)$. O Tipo de Instrução com instrução incompleta ofereceu mais respostas "Sim" $(0,33)$ do que o com instrução completa $(0,27)$. Quanto aos Modelos o Teste de Newman-Keuls mostrou que o Modelo 3 ofereceu mais respostas "Sim" do que os Modelos 1, 4, 5 e 6 $(p<0,01)$ e do que o Modelo $2(p<0,05)$.

3.2. Para as histórias Inválidas apenas Modelos apresenta-se como significativo: $(F(5,380)=4,48, p<0,001)$. Os resultados do teste de Newman-Keuls denotou que o Modelo 3 obteve significativamente maior número de respostas "Sim" $(p<0,01)$ nas histórias, do que em todos os outros modelos.

3.3. Quando se observam juntamente as histórias Válidas e Inválidas, efeitos significativos aparecem em Curso $(F(1,76)=5,93, p<0,02)$; Tipo de Instrução $(F(1,76)=$ $4,42, p<0,039)$; e Modelos $(F(5,380)=10,20, p<0,000)$. Os informantes do curso de Letras conseguiram melhores resultados e, quando receberam a Instrução Completa, os informantes foram superiores àqueles que receberam Instrução Incompleta. O curso de Matemática conseguiu maior número de respostas "Sim" (média 0,35 ) do que o de Letras (média 0,27). Aqueles que receberam Instrução Incompleta obtiveram mais respostas "Sim" (média 0,34) do que aqueles que com Instrução Completa (média 0,28). $\mathrm{O}$ teste de Newman-Keuls mostrou o Modelo 3 com significativamente maior números de respostas "Sim" do que o Modelo 1, 4, 6 e $2(p<0,01)$ e do que o Modelo $5(p<0,05)$. O Modelo 5 também apresentou melhor resultado do que o Modelo $1(p<0,01)$ e Modelo $4(p<0,05)$.

\section{Discussão}

\section{Tarefa de Conclusão}

Esta discussão terá início com uma breve análise do desempenho dos informantes quanto à questão de compreensão das premissas. O desempenho dos informantes foi de forma geral satisfatório para os informantes de Matemática $(72 \%)$ e para os informantes de Letras $(76 \%)$, o que reafirma que o leitor adulto realiza inferências lógicas necessárias para conclusão de silogismos subjacentes ao texto. Esta investigação confirma os resultados encontrados por Lea et al. (1990), quando afirmam que não há dificuldade dos informantes em realizarem inferências lógicas para compreender os textos. Esta facilidade é confirmada em relação ao conteúdo das histórias, que poderia impedir conclusão satisfatória por parte dos informantes, caso o silogismo envolvesse fatos desconhecidos ou que contrariasse as convicções religiosas dos mesmos (ver Dias, 1996 e Santos, 1996).

Foram detectados efeitos estatisticamente significativos na tarefa de Conclusão (tarefa de compreensão das premissas), para Sexo, Modelos e Tipos de História. Faz- 
se necessária uma análise da possível causa destes efeitos.

A diferença encontrada no fator Sexo expressa-se no sentido de que os informantes do sexo feminino obtiveram maior média de acertos, nesta tarefa, do que os informantes do sexo masculino e poderia estar justificada na sua relação com o fator Curso. Existindo interação entre Curso e Sexo, observa-se que a diferença de Sexo anula-se quase totalmente no curso de Letras, (Figura 2) o que não acontece em Matemática, pois os números nesse curso mostramse elevados para feminino (média 4.90) em relação ao masculino (média 3.62).

Assim, nos números encontrados e comparados intersexo em cada curso, observa-se que os informantes masculinos (média 4.70) de Letras apresentam uma diferença sutil em relação aos femininos (média 4.62), o que não acontece em relação ao curso de Matemática, no qual os informantes femininos demonstram um melhor desempenho.

O efeito dos Modelos no desempenho dos informantes é demonstrado através dos números encontrados nas respostas aos seis esquemas lógicos subjacentes às histórias utilizadas. Assim, os Modelos 3 e 5, que receberam mais respostas corretas para concluir o silogismo do que o Modelo 6. Com as histórias válidas os Modelos 1, 2, 3, 4, e 5 receberam mais resposta "Sim" do que o Modelo 6.

Para entender as histórias, o leitor precisaria acionar a memória semântica recorrendo tanto aos conhecimentos sobre os quais fala o conteúdo, quanto aos conhecimentos lingüísticos que observam o significado das partículas lógicas OU, SE, e "Não". Finalmente, precisaria utilizar estratégias de raciocínio com as quais eliminaria alternativas, descobrindo contradições e fazendo suposições. Desta forma, para oferecer conclusão, os informantes enfrentaram dificuldades tanto de ordem lingüística, quanto de ordem lógica.

Nas histórias válidas, a justificativa plausível para os números encontrados, que colocam as histórias dos Modelos 3 e 5 como aquelas que mais receberam respostas afirmativas para a conclusão do silogismo, está relacionada com a sua estrutura organizacional com a condicional SE, que oferece mais pistas para a compreensão das premissas. O Modelo 5 que ocupa o segundo lugar quanto às respostas corretas, apresenta estrutura similar ao Modelo 3, isto é, organização lógica com o hipotético SE. Essa mesma estrutura aparece no Modelo 2, contudo este se apresenta como o modelo que recebeu menos respostas corretas numa posição anterior apenas para o Modelo 6. Isto se justifica, ao se observar que a validade do silogismo do Modelo 2, exige do informante raciocínio da junção do SE e da negativa "Não" (se existe M ou K, então Não W) e ainda mais, uma afirmativa baseada em duas negativas (é falso que não existe $\mathrm{K}$ ), entende-se pois se é falso que não existe $\mathrm{K}$ é porque existe $\mathrm{K}$.

Concretizando o conteúdo, entende-se que na história "Sociologia", Modelo 2, Célia teria que conseguir B em uma nota e entregar o trabalho na data certa, com o qual não poderia tirar menos de C. O comentário de Carlos foi que ““Não” havia como Célia não entregar o trabalho na data combinada". Desta forma duas negativas, formariam uma afirmativa e Célia satisfaria as exigências. Tudo isso deixou o Esquema 2 com mais dificuldades que os outros esquemas, pois os Modelos 4 e 1 oferecem apenas os disjuntivos OU com o negativo "Não".

O Modelo 6 apresentou estrutura lógica mais diferenciada, que talvez justifique sua colocação em último lugar nas respostas dos informantes para a tarefa de conclusão. Neste modelo, para responder ao silogismo, o informante teria que conjugar um item com outros três, para depois eliminar um destes itens na dependência de um quinto item. A organização do modelo depende, desta forma, de "Sara cursar Arte, com outras disciplinas inclusive Biologia, dependendo (SE) de seu ex-namorado também não se inscrever nesta disciplina”. A conjunção de uma disciplina com possíveis outras três, sendo essa possibilidade determinada pela inclusão de um quinto item talvez tenha induzido o leitor a não relacionar as premissas dificultando-lhe encontrar a conclusão adequada.

Os resultados encontrados pelo Teste de NewmanKeuls mostraram significativamente mais respostas corretas para os Modelos 3 e 5 em relação ao Modelo 6 com as histórias válidas e inválidas tomadas em conjunto. Estão ainda em sintonia com o que foi encontrado na análise dos Modelos, isto é, existe para os informantes, na conclusão do silogismo mais dificuldades na estrutura organizacional dos modelos que, além da condicional $\mathrm{SE}$, envolvem duas negativas para se chegar a uma afirmativa.

Desta forma, observa-se que o leitor utiliza determinado modelo mental para concluir silogismos subjacentes ao conteúdo do texto e que o nível de dificuldade encontrada depende da estrutura organizacional do modelo. As 12 histórias utilizadas neste experimento formaram pares por modelo lógico, isto é, o modelo era único por par de história mas o conteúdo era diferente. Todos os informantes responderam a seis modelos lógicos, havendo diferença de resultado quanto ao conteúdo dentro do par de história.

Não parece explicação válida responsabilizar o conteúdo das histórias pelas diferenças encontradas nas respostas dos informantes em relação a tipos de história, mas a conclusão inválida parece favorecer concluir afir- 
mativamente as premissas dadas, pois elas violavam um conhecimento de mundo inerente aos informantes.

O conteúdo de uma das histórias do problema 3 é um jantar e o problema consiste em servir ou não carne. Acontece que duas das pessoas presentes, sendo vegetarianas, não podiam, obviamente, comer carne. Para esta história, a resposta inválida foi "Tudo certo, assim podemos servir carne", uma conclusão contrária ao conhecimento empírico do leitor. A outra história, "Cáries", também do esquema 3, mostra que a diminuição do número de cáries depende de usar flúor e comer chicletes sem açúcar. Esta, no entanto, recebe como conclusão inválida, "Se eu usar flúor todos os dias e comprar chicletes sem açúcar, eu terei cáries novas quando for ao dentista". As afirmativas contidas nessas conclusões violam o conhecimento de mundo do leitor de que vegetarianos não comem carne e que flúor protege os dentes.

Daí justifica-se o efeito significativo encontrado para tipos de história nos Modelos 3 e 5, quando se analisa os resultados encontrados nas outras histórias cujas alternativas oferecidas para escolha das respostas eram indiferentes em relação ao conteúdo das histórias, não fornecendo pistas que favorecessem uma conclusão satisfatória. Observa-se no problema 6, distanciamento entre os tipos de histórias: as inválidas apresentaram o resultado de $81 \%$ com queda bastante acentuada nas histórias válidas de $53 \%$. Este modelo (6) recebeu, entre as válidas, o escore mais baixo e, entre as inválidas, o escore mais alto corroborando o discutido anteriormente, que foi o modelo a dificultar a conclusão do silogismo, daí determinar estatisticamente a interação entre Modelos e Tipos de história. Este resultado e aqueles discutidos nas histórias 3 e 5 podem ser interpretados como dados a reforçarem a idéia de que a conclusão dos silogismos inseridos em textos pode sofrer influência da organização semântica das sentenças e dos modelos lógicos subjacentes.

Os resultados da Tarefa de Conclusão responsabilizam a estrutura dos Modelos lógicos utilizados pela diferença encontradas em seus números. Os modelos com negativa e principalmente organizados com duas negativas impedem que os informantes completem logicamente os problemas apresentados. Também apontam que os informantes foram beneficiados pelos problemas quando a sentença inválida violava o conhecimento empírico.

Em virtude de os resultados terem acusado que os informantes de Letras, em relação aos informantes de Matemática, tenham demonstrado melhor desempenho nesta tarefa, fica a sugestão para estudos posteriores relacionarem a diferença encontrada com as disciplinas presentes em cada curso, para que sejam descobertas as justificavas bem consistentes para os resultados encontrados.

\section{Tarefa de Reconhecimento}

A tarefa de Reconhecimento investigou se as informações recuperadas da memória do leitor, logo após a leitura, são textuais ou resultado de informações implícitas realizadas. Os números encontrados permitem efetuar estudos em diferentes direções: avaliar distâncias encontradas nos números entre as instruções, determinar as divergências numéricas apresentadas nos seis modelos lógicos e, finalmente, avaliar os resultados dos itens, isto é, analisar a preferência dos informantes por um deles.

A tendência dos informantes de produzir três respostas "Sim" ou três respostas "Não", não se manifestou na direção de nenhum par de história. Os resultados apontam que a Paráfrase teve maior número de resposta "Sim" em relação a Modelos e Não-modelos, e Modelos mais respostas "Sim" em relação a Não-modelo. Estes resultados ratificaram aqueles encontrados por Lea et al., e observa-se que no item Modelo os informantes se aproximavam mais do item Paráfrase do que do item Não-modelo.

O item Paráfrase teve suas sentenças em quase todos os modelos, correspondentes a uma única sentença do texto. Isto facilitou para que recebesse mais resposta "Sim" para reconhecimento de sua presença no texto. Nos testes com este item não foi apontado efeito significativo para o fator Tipo de Instrução (instrução incompleta e completa) em nenhum tipo de história.

Quanto ao fator Curso, os resultados dos testes realizados com a paráfrase demonstram que os informantes do Curso de Letras obtiveram um percentual maior de respostas "Sim" (73\%) do que o de Matemática (61\%). Esta análise demonstrou para este fator, Curso, efeitos significativos, nas histórias válidas, nas inválidas e nas válidas e inválidas tomadas em conjunto.

As atividades realizadas no estudo não oferecem condições que justifiquem o efeito encontrado, ou seja, os informantes de Letras apresentarem melhor desempenho no reconhecimento das sentenças do que os informantes de Matemática. A justificativa para a diferença entre cursos não pode ser encontrada nos diferentes modelos, pois os informantes de Matemática mostraram-se aquém dos de Letras em todos os modelos. Uma possível responsabilidade, dentro desta tarefa de Reconhecimento, talvez caiba à capacidade de memória do leitor pois ele terá de reconhecer sentenças já lidas. Estudos anteriores (Paris \& Carter, 1973, citado em Yuill \& Oakhill, 1991), declaram que crianças demonstram maior capacidade de memorização relacionada com as idéias do texto, do que propriamente com as palavras do texto. O objetivo de Paris e Carter foi investigar a memória como um dos aspectos responsabilizados no processo de compreensão 
de texto. Por conseguinte, quando se pretende investigar um outro aspecto, qual o tipo de informação, textual ou inferencial, é melhor estocada na memória do leitor, a seleção das atividades deve ser rigorosa. Não existem estudos anteriores que tenham procurado investigar se a capacidade de memória de universitários que cursam áreas diferentes apontam números significativos em relação ao Curso. A discussão exige pesquisas posteriores em uma investigação sobre memória semântica com informantes de diferentes cursos, necessitando controle de variáveis que interfiram nestes resultados.

$\mathrm{Na}$ interação do item Modelo com Curso, Modelos e Tipo de Instrução a análise demonstrou significância para Tipo de Instrução nas histórias válidas e também nas histórias válidas e inválidas juntas. Instrução Completa obteve maior número de respostas "Sim" do que o Grupo com Instrução Incompleta, confirmando a hipótese inicial de que os informantes seriam influenciados pela observação “...mesmo que não seja palavra por palavra”. O fator Curso novamente aponta diferenças significativas quando o curso de Matemática obteve menor número de respostas "Sim" nas histórias válidas e inválidas tomadas em conjunto, do que o Curso de Letras, sugerindo que pesquisas posteriores sejam conduzidas para que se encontrem justificativas para esses resultados.

Em relação a Não-modelo, foram encontrados efeitos significativos para Curso, com histórias válidas e histórias válidas e inválidas tomadas em conjunto, isto é, os informantes Matemática ofereceram maior número de respostas "Sim" do que os informantes de Letras. A variável Instrução neste item ratifica os resultados encontrados nos outros dois, de que a Instrução Completa beneficiou o informante na identificação da sentença. $\mathrm{O}$ informante diminuiu sua responsabilidade em relação às palavras do texto e procurou apoiar suas respostas no conteúdo das sentenças.

Analisando os resultados apresentados pelos informantes para o fator Modelos, observa-se que suas respostas apontam diferenças e semelhanças em cada item e elas podem ser explicadas pela estrutura sintático-semântico das sentenças para reconhecimento.

Assim, para o item Paráfrase com as histórias válidas, o Modelo 1 (Teste de Física e A Lâmpada) obteve maior número de respostas "Sim" do que os Modelos 5 e 3. Já nas histórias válidas e inválidas em conjunto, novamente o Modelo 1 obteve maior número de respostas "Sim" do que os Modelos 3 (Cáries e O jantar), 4 (A viagem e Discos) e do que o Modelo 5 (Segurança e As Bolachinhas) nos itens Paráfrase e Modelo.

Também no item Modelo as histórias dos Modelos $1 \mathrm{e}$ 2 obtiveram a preferência dos informantes recebendo maior número de respostas "Sim" nas histórias inválidas e no con- junto de histórias válidas e inválidas em relação as histórias dos modelos 3 e 4 .

Os números resultantes dos testes realizados para $\mathrm{Pa}-$ ráfrase e para Modelo, apresentaram coincidência de resultados que fortemente apontam causas que lhes podem ser comuns. Os Modelos 1 e 2 sempre se colocaram em melhor posição do que os Modelos 5, 3 e 4. Observe a história “A lâmpada" Modelo 1, em que a sentença resposta Modelo "O arame de conexão estava bom" é de fácil relação com as informações do texto. A história "Teste de Física", também Modelo 1, apresenta suas sentenças Paráfrase e Modelo em períodos curtos, relacionadas com um único período do texto, enquanto a sentença Não-modelo não encontra um período correspondente na história. As histórias "Sociologia e Holmes", Modelo 2, apontaram maior número de respostas "Sim" dos informantes para o item Modelo; rejeitando a Paráfrase que possui suas sentenças com número maior de palavras do que o item Modelo. O item Paráfrase no entanto suas informações apresentadas em um único período nos textos. Tudo isso levou o Modelo 2 receber maior número de respostas "Sim", do que tanto o Modelo 3 nas histórias inválidas, quanto nos modelos 3 e 4 nas histórias válidas e inválidas tomadas em conjunto.

O que é interessante observar, em relação ao item Não-modelo, é terem sido as histórias do Modelo 3 significativamente melhores que os modelos 1 e 2 que se evidenciaram em paráfrase e em Modelo. O Modelo 3, no item Não-modelo com as histórias válidas eliciou significativamente mais respostas "Sim" do que todos os outros pares de história nos modelos (1, 4, 5, 6 e 2). Nas histórias válidas e inválidas tomadas em conjunto, o Modelo 3 ofereceu maior número de respostas "Sim" em relação aos modelos 1, 4, 6, 2 e 5, enquanto o Modelo 5 mostrou-se significativo para os modelos 1 e 4 . No item Não-modelo o Modelo 3 mostrou-se bem significativo, e suas histórias devem ser analisadas. As sentenças de "Cáries" (Modelo 3), como já exposto anteriormente, são estruturadas em períodos longos e correspondem a períodos diferentes nos textos, apresentando igualdade estruturais entre as três sentenças dos itens (Parágrafo, Modelo e Não-modelo). Logo, os três itens oferecem as mesmas dificuldades, no entanto, o item Não-modelo, contém a informação principal do texto, o que facilitou seu reconhecimento.

As três sentenças Não-modelo das histórias do Modelo 1 apresentam dificuldades que se distanciam. A sentença de "Teste de Física" é expressa em um período curto, porém não se revela nas informações do texto, isto ela é resultado de uma inferência. A sentença de "A lâmpada" em sua mensagem desmente as informações da sentença do Modelo, porém a dificuldade para o leitor talvez esteja 
no conteúdo, o reconhecimento da sentença pode sofrer influência do não conhecimento do assunto, eletricidade.

As sentenças do Modelo 4 não apresentam similaridade superficial em seus termos lexicais com as histórias e, além disso, desmentem informações contidas no texto (como em "A viagem", a sentença "Eles não podem ir à Califórnia nem a Hong Kong", apesar de o texto apresentar que "Dona Lúcia queria ir aos dois lugares embora não tivesse tempo"). Assim ela iria ou a um lugar ou ao outro.

No Modelo 5 as histórias paralelas apresentam características diferentes. Em "Segurança", a Não-modelo é a mais longa das três sentenças sendo necessário o informante integrar informações que se espalham dentre vários períodos nas histórias para fazer o reconhecimento. "As bolachinhas" tem a sentença Não-modelo numa estrutura com muitas palavras, porém integra a informação principal do texto. Talvez tenha sido esta história responsável pela significância do Modelo 5 no item Nãomodelo. Desta forma, enquanto uma sentença reduz o número de respostas "Sim" em virtude de apresentar-se em período longo sem similaridade com um período do texto, a outra possibilita um número considerável de resposta "Sim" por conter a informação principal do texto.

As sentenças do Modelo 6 ("Xavier" e "Plano de estudo") também separam suas histórias quanto à sua estrutura, demonstrando que os informantes na tarefa de Reconhecimento não sofreram influência do modelo lógico para a escolha de sua resposta, porém são levados pela capacidade de memória semântica ou visual que possuem. A sentença Não-modelo de "Xavier" (Modelo 6) traduzia a última frase lida do texto e por conseguinte estaria mais clara na memória do leitor. As sentenças Não-modelo de "Plano de estudo" (Modelo 6) que recebeu menos respostas "Sim", teve suas informações não-condizentes com o texto, perdendo assim para Paráfrase e Modelo que retrataram informações textuais.

No item Não-modelo, são apresentadas justificativas novas que não legitimam a escolha do informante em algumas histórias, mas também fundamentam os resultados encontrados para as sentenças de alguns modelos.Dentro deste item, observou-se que, quando as sentenças continham a idéia principal do texto, receberam maior número de respostas "Sim", corroborando o já declarado por Paris e Carter (1973, citado em Yuill \& Oakhill, 1991) de que crianças retêm as idéias de um texto mais do que as palavras nele contidas.

Assim, a fonte mais importante quanto às informações parece ser um traço comum encontrado nas histórias: o número de palavras em que a informação é apresentada. A explicação, em potencial no presente estudo, diz respeito à possibilidade de que o desempenho na tarefa de Reconhecimento pode ter sido facilitado pela estrutura de suas sentenças por terem suas informações apresentadas em um único período da história.

Lea et al. (1990) usaram duas medidas de similaridades para comparar as sentenças de reconhecimento e os textos. As duas medidas consistiram de um percentual de palavras nas sentenças dos três itens as quais correspondessem em maior ou menor quantidade às palavras das sentenças do texto. Nenhuma estratégia possível, porém, favoreceu um ou outro item do Reconhecimento, então não consideraram as similaridades superficiais justificativas convincentes para os seus resultados. Esta similaridade lingüística nas histórias traduzidas e utilizadas no presente estudo, quando se observa equivalência de palavras não se constitui também suficiente para justificar os resultados encontrados da interação dos três itens (Paráfrase, Modelo e Não-modelo) e os seis pares de história, corroborando a justificativa de Lea et al. A fonte principal das dificuldades parece estar no número de sentenças dos textos que são usadas para fazer emergir as sentenças de reconhecimento.

A segunda tarefa revelou dificuldades que podem ser sintetizadas em dois aspectos. a) em relação às três sentenças: estruturação dos períodos em longos ou curtos; utilização de sinônimos em lugar da mesma palavra do texto; e finalmente o reconhecimento de sentenças que no texto tenham suas informações contidas em mais de um período; b) em relação ao leitor: conhecimentos pragmáticos do leitor, interferem no inferenciamento, levando-o a aceitar como retiradas do texto informações registradas anteriormente na sua memória.

Nesta tarefa constatou-se que o informante, pelas respostas dadas não identifica a origem de suas respostas, ficando a sugestão para estudos posteriores investigarem em relação ao leitor o que the dificulta reconhecer informações textuais ou explícitas depois da leitura. Se é claro que as inferências são necessárias e têm sua realização automática e espontânea por parte do leitor/ouvinte, não é muito claro como detectá-las sobretudo de que modo estudá-las.

\section{Agradecimentos}

Os autores agradecem ao CNPq e e à FACEPE pelo financiamento da pesquisa que originou este trabalho.

\section{Referências}

Braine, M. D. S., \& Rumain, B. (1983). Logical reasoning. In J. H. Flavell \& E. M. Markman (Orgs.), Cognitive development, carmichael's manual of child psychology (Vol. III, $4^{\mathrm{a}}$ ed., pp. 263-289). New York: John Wiley \& Sons.

Carraher, D. W. (1983). Senso crítico. São Paulo: Pioneira.

Dias, M.G.B.B. (1996). O desenvolvimento do raciocínio dedutivo. In M.

G. B. B. Dias \& A.G. Spinillo (Orgs.), Tópicos em Psicologia Cognitiva (pp. 11-44). Recife: Editora Universitária. 
Goodman, K. (1967). Reading: A psycholinguistic guessing game. Journal of the Reading Specialist, Maio, 126-135.

Marcuschi, L.A. (1989). O processo inferencial na compreensão de textos. (Relatório 30.4780/85), Mimeo, Recife.

Kleiman, A. (1997). Texto e leitor: aspectos cognitivos da leitura ( $\left.5^{\mathrm{a}} \mathrm{ed}.\right)$. Campinas: Editora da UNICAMP.

Lea, R. B., O’Brien, D. P., Fisch, J. A., \& Braine, M. D. S. (1990). Predicting propositional logic inferences in text comprehension. Journal of Memory e Language, 29(3), 361-387.

Lima, M. E. M. F. (1983). Compreensão de leitura de narrativa em crianças - Um estudo sobre pensamento inferencial. Dissertação de mestrado, não-publicada, Universidade Federal de Pernambuco, Recife.
Oakhill, J, Cain, K., \& Yuill, N. (1994). Individual diferences in children's comprehension skill: Towards an integrated model. Paper presented at the NATO Advanced Study Institute: Cognitive and Lingüistic Bases of Reading, Writing and Spelling, Portugal.

Piaget, J. (1972). Intelectual evolution from adolescence to adulthood. Human Development, 15, 1-12.

Santos, C. M. M. (1996). Good reasoning: to whom? When? How?: An investigation of belief effects on syllogistic and argumentative reasoning. Tese de doutorado não-publicada, University of Sussex, U. K.

Yuill, N., \& Oakhill, J. (1991). Children's problems in text comprehension. New York: Cambridge University Press.

Notas

$1 \quad$ Pode ser representado por uma única palavra ou conjunto de palavras que encerre um pensamento completo. No texto escrito é sempre finalizado, pelos sinais de pontuação (.), (!) e (?).

2 Antes desta análise, visando aumentar o poder de análise, foi computada preliminarmente uma Análise de Variância similar tendo como fatores somente as variáveis Ordem e Sexo. Visto que somente a variável Sexo produziu um efeito significativo, esta variável continuou fazendo parte da Análise de Variância posterior.

3 Antes destas análises, visando aumentar o poder de análise (como na análise da Tarefa de Conclusão), foi computada preliminarmente uma Análise de Variância similar tendo como fatores somente as variáveis Ordem e Sexo. Visto que tanto a variável Ordem como a variável Sexo não produziram efeitos significativos, ambas não foram consideradas nas análises subseqüentes.

Amariles Alves Rodrigues é mestre em Psicologia pela Universidade Federal de Pernambuco, exbolsista do CNPq e FACEPE.

Maria da Graça Bompastor Borges Dias, doutora em Psicologia do Desenvolvimento pela University of Oxford (Reino Unido), é professora do Departamento de Psicologia da Universidade Federal de Pernambuco.

Antonio Roazzi, doutor em Psicologia pela University of Oxford (Reino Unido), é professor do Departamento de Psicologia da Universidade Federal de Pernambuco.

Endereço para correspondência: Av. Beira Mar, 520 ap.81, Piedade, 54310-064, Jaboatão, PE. Telefone (081)3271.8272; Fax (081)3271.1843; E-mail: [MGBBD] mdias@npd.ufpe.br. 